\title{
Closing the Gap Between Research and Practice: Conversation as a Mode of Doing Research
}

\author{
Terrance R. Carson \\ University of Alberta
}

It is well known that the language of research and the language of practice differ as to their audiences and purposes. Research is intended to provide generalized information to a broad audience of educators. The consumers of such generalized research information are those who have the interest and the authority to make use of it; normally, this includes other researchers, legislators, administrators, and the granting agencies who must make large scale system decisions. In contrast, the language of practice is contextually bound to specific situations in which the individual practitioner must act as a responsible agent. Frequently, the educational practitioner is disdainful of generalized findings, dismissing them as being "fine in theory, but not like that in practice."

Why this is so should not be surprising. A number of years ago studies like Jackson's (1968) and Lortie's (1975) showed that the rewards and the problems of teaching are localized and individualized. Small wonder that some recent evaluations have indicated that research based innovations have had relatively little impact on changing conventional school practices (Berman \& McLaughlin, 1976; Cuban, 1982; Popkewitz, Tabachnik \& Wehlage, 1982; Goodlad, 1984). A few subsequent studies have been somewhat less pessimistic about the amount of influence, but they have also pointed out that the relationship between research and practice is far more complex and ambiguous than it had earlier been assumed to be (Crandall, 1983; Fullan, 1982; Carson, 1984).

More sophisticated understandings of the complex relationship between research and practice has brought about a liberalization of accepted modes of research. However, the development of new research paradigms has not only failed to close the gap between research and practice, it has also brought about new problems of communication amongst researchers. Mosenthal (1985) indicates that a major source of miscommunication arises because educational phenomena can only be partially defined. This makes possible alternative definitions of what constitutes progress towards improving practice. According to Mosenthal, deciding a good relationship between research and practice depends upon three possible definitions of progress: a literal definition which looks for a verisimilitude between operational descriptors and the phenomena, an interpretive definition given by the participants, and an evaluative defini- 
tion in which progress is understood in terms of ideologically based criteria that are made explicit by the researcher.

While Mosenthal's schema helps to describe paradigms of research, it does not explicate the differing stances that each takes on the question of practice. We are left with a kind of relativism, where the meaning of progress depends upon one's perspective. This may help us to understand present conflicts, but it leads us no closer to our original concern that research should actually improve practice.

The four studies reported on in this paper fall within Mosenthal's definition of interpretive studies, but as I shall argue later, they do not simply represent one perspective amongst others. Each of these studies explicitly adopts a normative stance which intends to influence the practice of the participants in the conversation.

As coparticipants in conversation with researchers, practitioners gain new vantage points on their practice. How this contributes to closing the gap between research and practice in a way which improves practice may be best illustrated by contrasting the conversational relation with the traditional data gathering technique of interviewing. The interview is designed to elicit information from informants concerning a topic which is of relevance to the researcher. How this information actually relates to the improvement of teaching practice as experienced by the practitioner is not of central importance since the data must be extracted from its situational meaning and recontextualized in the form of generalizations which have a wide application.

I will explore the use of conversation as a mode of curriculum research with reference to four doctoral studies recently completed in the Department of Secondary Education at the University of Alberta. These studies are as follows: Favaro (1982) on the meaning of consulting, Smith (1983) on the meaning of living with children, Peterat (1983) on the meaning of teaching home economics, and Carson (1984) on the meaning of curriculum implementation. Each of these studies is informed by an explicit intention to move away from positivistic forms of research in order to forge new understandings and to develop new platforms for practical action. This intention is marked by an awareness that positivistic research is inadequate to the task of an educational practice which demands both performance excellence as well as an orientation to "the good"-what has been called "practical philosophy" (Gadamer, 1981 , p. 98) or "pedagogical theorizing" (van Manen, 1982). Thus a conventional notion of method is also called into question as these researchers have attempted to come to an understanding of what forms the basis of both curriculum research and teaching.

\section{Conversation as a Hermeneutic Activity}

Each of these studies are guided by an understanding that establishing a conversational relation is a hermeneutic endeavor. Such a view 
is rooted in Gadamer's philosophical hermeneutics which considers interpretive acts in their widest possible sense as the ontological task of understanding the nature of human being-in-the-world. When it is applied to curriculum research, philosophical hermeneutics allows us to understand that curriculum theorists and inquirers do not begin their thinking and research from scratch. Persons interested in such issues partake in a continuing and evolving conversation on curriculum theory and classroom practice which has begun long before their arrival and which now continues with their participation. Thus we enter into a particular aspect of what Michael Oakeshott (1959) has called "the conversation of mankind."

Experience has shown that new curricula are notoriously difficult to implement. Teachers consistently ignore the intentions of the curriculum developers, borrow and modify only those parts of a new program which fit their beliefs. Conventional research has focussed directly on how curricula do or do not get implemented by discovering the various blocks to, and determinants of, effective implementation (see for example the work of Leithwood, 1982, Fullan, 1982, and various studies by Hall and Loucks). However, the application of this knowledge about implementation to school settings has been a mixed blessing for teachers. On one hand, it has helped to expose the complexity of school change and the need to provide time and resources to inservice teachers. On the other hand, this information has also been used to exercise a finer and more complete control over teachers' work. One way of using the knowledge is helpful to teachers, the other is not.

By treating either curriculum implementation or the nature of teachers' practical knowledge as objects of investigation, attention is diverted from the deeper question that might present itself to us as a realization that we really do not know how to carry out school reform without placing further controls on teachers' practice. This points to a more basic crisis of human action within institutionalized education, a dilemma which goes to the roots of educational research as it relates to practice.

Research based in a philosophical hermeneutics approaches the difficulty of school reform differently. Recognizing that all questioning arises out of the negativity of experience, that is, that things are not as we had assumed them to be, hermeneutic inquiry begins with an attempt to understand the question itself. This is what Gadamer has referred to as "the hermeneutical priority of the question" (1975, p. 325). It holds that research problems which appear in various guises as how to implement effectively new programs, are in fact not true questions at all, but are statements of opinion, and that the answer lies in the direction of making teachers' practice more accessible to externally mandated change. 
Hermeneutic interpretation begins not with direct research into the problem, but with an uncovering of the question to which the problem statement is an answer. This process is inherently conversational in that the participants in the conversation seek to deepen their understanding of the topic of conversation itself. Gadamer (1975) describes it thus:

To conduct a conversation means to allow oneself to be conducted by the object to which the partners in conversation are directed. It requires that one does not try to out-argue the other person, but that one really considers the weight of the other's opinion. Hence it is an art of testing. But the art of testing is the art of questioning ... to question means to lay open, to place in the open. As against the solidity of opinions, questioning makes the object and all its possibilities fluid. (p. 330)

\section{Coming to the Question}

Interpreting the prior question which lies behind a problem statement is not totally an analytical process. There is an experience of the world which directs our attention to the question in the first place. Autobiographical reflection is, therefore, an important aspect of research in a conversational mode. In my own case (Carson, 1984) my interest in curriculum implementation originally comes from the experiences that I had as a teacher working on local and provincial curriculum committees, and subsequently becoming a school district curriculum supervisor. My interest was in how to relate the intentions and the deliberations which go into the curriculum documents to classroom practices.

My partners in conversation in the research were three consultants and three teachers engaged in the implementation of a new provincially mandated social studies curriculum. The actual conduct of the conversation was carried out and sustained by placing in the open the various activities associated with implementing this new curriculum alongside the meaning of teaching for the participants. Many concrete examples of the differences between the intentions of the curriculum and the way that these were translated in the documents and inservice sessions were drawn out during the conservations, as were related examples from other experiences. The recounting of experiences, mine and theirs, and a theorizing on these experiences enabled us to come to the question: What is the real relationship between teaching and curriculum?; and, why do we answer this relationship as we do in curriculum implementation practices?

A negativity of experience also enabled Favaro (1982), Peterat (1983), and Smith (1983) to come to the questions of their studies. Favaro's interest in consulting and inservice education was rooted in his work as a coordinator of a regional university's department of continuing education. $\mathrm{He}$ and the participants in his study, five 
teacher educators and school administrators, entered into a conversation about the meaning of consulting for them and how it compared with an instrumentalist research literature which seemed to ignore their experience that consulting is essentially a human relationship between educators. By recalling and reflecting on experiences of having given and having received a variety of forms of consultative help, the partners in Favero's conversations were able to begin to consider seriously the question of what would constitute meaningful consultative relationships within the school systems served by the department of continuing education.

As a former high school teacher Peterat arrived at the question of understanding curriculum as a lived reality in the lives of home economic teachers. The curriculum literature she had come to know as a doctoral student had a tendency to view the teacher as deficient and as an object for action. This did not reflect her own experience of teaching. The opportunity to probe these contrasting views of teaching further came about as she entered into conversation with two home economics teachers while they were piloting a new curriculum. The situation of piloting provided a suitable venue for questioning the relationship as these alternative views of teaching confront one another in the process.

Smith's study asks, "What is the meaning of children in the lives of adults?" (1983). The explicitly autobiographical roots of this question are located in Smith's own experiences as a student of theology and as a teacher and childcare worker in a home for emotionally disturbed children. These experiences have allowed him to become aware of a dangerous split between the academic language of scholarship and "what it is" that the language speaks about. Smith sees this manifested in contemporary Protestantism as the possibility of being correct theologically speaking, but personally lacking in those very qualities of which one speaks. The same disembodied language exists in the literature on childcare. This, he notes, reflects something of "a state of emergency existing in adult-child relations" (Smith, p. 3). We grasp for advice on parenting and teaching while the language of caring is rooted in a relationship with children as "objects of inspection" rather than as they live of our own flesh and blood. The questioning of what children mean in the lives of adults marks an attempt to reestablish this language.

Smith engaged in conversation with 15 different adults who experienced children in quite different ways from one another. The participants included persons with children and those without children, married and unmarried, professional childcare workers and parents, older parents and younger parents. Of the four studies, Smith's is the most self-consciously reflective. He comes to the question of a hermeneutical inquiry of modern life and culture in much the same spirit as Gadamer has redefined the task of hermeneutics as a philosophical reflection on being-in-the-world. 
In none of the studies is the research question simply an identification of the objects of research. The questioning is a matter of personal commitment and reflection on what one should do. These studies centrally concern how to conduct one's personal and professional life as a curriculum scholar. In this sense, conversation is a moral discourse among colleagues who are members of the community.

Research as a mode of practice can be distinguished from conventional research in two important ways: First, the moral content is immanent to the questioning itself and not added on in the application to practice; and second, there is no sharp division between the private and the public life of the participant.

\section{Conducting a Conservation}

There is no actual separation between the activity of coming to the question and the conduct of the conversation itself. The underlying question emerges in the dialectic of question and answer. However, the nature of the conversational question is quite different from the interview question. The latter involves an effort to gather information about perceptions or practices. The former implicates a revealing of something held in common. Gadamer (1975) states it like this:

What emerges in its truth is the logos, which is neither mine nor your's and hence so far transcends the subjective opinion of the partners to that dialogue that even the person leading the conversation is always ignorant. Dialectic as the art of conducting a conversation is also the art of seeing things in the unity of an aspect, i.e., it is the art of the formation of concepts as the working out of the common meaning. (p. 331)

The research stance is one of allowing the meaning to emerge through the language. So the actual questioning is an interrogation of the way that we speak about the topic under discussion. To allow the language to perform this function, it is necessary that the openness of the question be preserved and not cut off too early by rapidly formed opinions and conclusions. Openness may be preserved by giving due consideration to what was reflected in the language of the conversation. The words spoken may then have a way of surprising both the researcher and the participant with unexpected insights.

How to maintain the openness of the conversation is both an art and a skill. There are quite lengthy accounts in each of the four studies of how the intention to preserve the openness of the conversation is mediated by the pragmatic requirements of doing doctoral research. Included are accounts of how the exigencies of time and access are negotiated with the participants. Also included are accounts of how those engaged in the conversational relation deal with former habits of the participant as informant-conventions of a technical research 
paradigm. While each study developed different strategies for negotiating these problems, a practice common to all was the requirement that transcript summaries of the conversations be kept to allow for reflection on the talk.

In the case of my own study, I identified topics of our conversation and provided summary transcripts of the dialogue under each topic. There were four conversations with each participant. Following my analysis of the first conversation, I would attempt to focus on the particular insights the talk had given into curriculum implementation, while raising still further questions for the second conversation. In this process the implementation practices being experienced by the participants was made available for reflection along with past experiences and future possibilities for improvements. One aspect of a sequence of conversations with a consultant, Linda, provides an example. I commented on our previous conversation as follows:

We talked of having the time (to dialogue with teachers about the curriculum change). This is necessary, you said, because you cannot represent the intent of the new curriculum properly in writing. This point has come up in many of my (other) conversations. I think that this alone points to one of the real questions. Why isn't time allowed? Why do we set things up in such a way where the consultant must be the presenter, the giver, the expert, in half-day inservices on some particular thing?

Linda responded by wondering the same things about time, but then she directed the conversation towards a questioning of various forms of expertise. Was it expertise in presentation or expertise in teaching that one looked for in a consultant? And how does one convey the latter? In the interchanges our attention began to focus on the contrasting logics of bureaucracy and teaching. This was a surprising, but not unanticipated, turn in the conversation. It was surprising in that it was the product of inductive sense-making, an insight drawn from exploring questions about time management, the meaning of expertise, and teaching. It was anticipated in the sense that we already had an intimate knowledge of bureaucracy and teaching, but had not fully understood the implications of how these relate and are lived out in our own work lives. By bringing this relationship to language we were able to place in the open an important aspect of what it means to work as a teacher in school systems as they are now constituted.

The conduct of conversation in the other studies shows a similar mutual questioning of a commonly shared world within which one acts as an educator. In Favaro's study, the conversations were conducted first as a series of personal discussions with each consultant/ administrator. In the initial encounter the participants engaged in what he termed an "inter-view" of the dialectic between consulting 
experienced as a "reconnection with the lived world of consultees" and consulting experienced as domination and control. In a second stage, each of the participants was able to read and discuss Favaro's interpretations of the experiences of each person involved in the study and to discuss these in a group conversation.

Peterat conducted a number of intensive conversations with two participants. The discussions were ostensibly about piloting a new curriculum, but the talk about piloting ranged far beyond this initial invitation to dialogue. Piloting is conventionally seen as a trivial run to test the feasibility of a new curriculum in practice. However, the try-out meant coming to terms with the meaning of the "new" in relation to their own teaching. Thus, piloting was an occasion for critical reflection. In particular, these teachers began to reflect, as women, on the kinds of pressures that they feel in balancing demands of family, career, and teaching.

During the course of the research Peterat also participated as an observer at the meetings held for the pilot teachers and she kept a journal for personal reflections on teaching and research. These personal reflections during the course of the conversations played a major role influencing the overall tone of the questioning, highlighting the contrast between the public and the private lives of being a person who teaches.

The talk in Smith's study begins with a hermeneutical conversation with individual adults concerning the personal meaning that children have in their lives. Each conversation opens with an invitation to the participant to talk about a particular child or children. Smith encourages the conversation to continue by asking further questions and picking up on new topics introduced during the course of the dialogue. Rather than pursuing this with the individuals beyond the initial conversations, he returns to the transcript as a "form of narrative life story." He then shows how the reconstructed narratives point beyond the actual words to a more essential being that is spoken through the discourse.

This pointing beyond what is said is a significant feature of curriculum research in a conversational mode. On the one hand, this openness and indeterminacy sustains the conversation, allowing it to proceed as a dialectic of question and answer. On the other hand, this is done as a peculiarly social form of discourse which does not conform to the conventions of the dialectic in the first instance.

\section{The Logic of Conversation}

Roland Barthes (1978) provides some helpful insights into the structure of conversations. Unlike writing, conversation does not have a linear logic. Conversation has an appearance of "discursus"of a running from place to place. Barthes also notes that the conver- 
sation has the character of "the almost [presque]" (Barthes, 1979, p. 3), never really specifying what it is about, but carried forward by the participants' efforts to discover what it is. Conversation is poetic in style. Participants do not ordinarily ask for proof of assertions. There are a profusion of examples, ostensive references and vivid recollections, but these are amicable rather than authoritative, lodged in the participants' primary interest in coming to some common understanding as to what the conversation is about.

Hermeneutical reflection requires that a critical distance be taken in order that what the language reveals may be placed into the open. This can be accomplished by imposing a more formal dialectic of question and answer. Gadamer suggests that in "real conversation" the words have a maieutic quality $(1975$, p. 330$)$ - they become like midwives helping to bring forth thoughts and ideas not hitherto present. However, the dialectic is not a part of the natural structure of conversation and it must, therefore, be consciously introduced by the researcher as a second layer providing the needed critical moment. In the actual conduct of research this is often accomplished by bringing contradictions to the attention of the participants. Such contradiclions may be found within the conversations by reflecting on the transcripts of earlier conversations.

\section{The Potential of Conversation as a Mode of Curriculum Research}

The potential that conversation has as a mode of curriculum research will depend upon whether or not it is regarded merely as an effective technique for data gathering or as hermeneutical reflection with a practical intent. A good many scholarly inquiries in the curriculum field have relied upon forms of talk between researcher and researched as a means of understanding aspects of practice. Conversation has been particularly attractive, both because of its richness and because it is a friendly and natural form of intercourse which allows for an easy exchange of experiences. But to treat the information merely as data does little to narrow the rift between research and practice in a way which will lead to good practice.

The popularity of qualitative research has created a rather unseemly rush to find a complementarity between it and quantitative research. As Smith and Heshusius (1986) have pointed out, such claims are based on a confusion of technique and methodology. Differences in technique are not really significant. What is significant is the differing logics of justification which underpin qualitative and quantitative methodologies. Quantitative method rests its justification on objectivist grounds independent of the meanings given to it by the participants. Qualitative methods find no such externally available certainty of explanation, but continue to press for better interpretations of meaning. According to Smith and Heshusius, claims for a complementarity on the basis of a commonality of tech- 
niques has lead prematurely to a closing down of a very productive discussion on the nature of educational research.

The comments by Smith and Heshusius indicate that interpretive research has established a different basis for deciding validity of research. However, hermeneutic research also establishes a different attitude to the application of research to practice.

The idea of application is central to hermeneutics in that it is an integral and necessary part of the interpretive process. To understand means that what is understood has a claim on us, we appropriate the meaning to our own thoughts and actions in some way. At this point, this is a rather vague statement, but it becomes more clear when contrasted with the technical idea of application which makes no such claim. In a technical sense information may be picked up and used, or not used, depending on the discretion of the user. In a hermeneutic sense understanding is not completed unless we see what is understood as applying to us in some concrete way.

The intents of the four doctoral studies to bridge the distance between the research community and a community of practitioners shows a way of regarding the role and goals of research. To apply conversation as a mode of research means to understand and commit oneself to a communal venture of discovering the "right" relationship with children, with one another, and with the wider community. Of course, it is possible to misunderstand and see conversation merely as an effective means for eliciting information from practitioners. But, true understanding is not like this, it requires a self-conscious realization.

The content of each study offers a variety of significant insights into aspects of practice, but a question remains as to how much these basically situational insights help curriculum studies. This is application in a more traditional sense.

In his study, Smith is explicit in his intention to escape the situational through his experiment in hermeneutical writing. This is a form of writing which seeks to identify ontological themes which invite further dialogue and, through this dialogue, the possibility of understanding children's lives "woven round and about" the lives of adults. The application that is immanent to this understanding leads to a deeper realization of the being of both adult and child.

Each of the other three studies is tied to a specific case of curricular practice. The conversations allow the participants to reflect on the meaning of this practice as it manifests itself in their experiences. The basic negativity of the experience of implementation, of consulting, and of piloting as compared with the institutional expectations these hold for improving curriculum and teaching give rise to the questioning. Because they are such common practices, these insights have a broad applicability to other situations. 
Favaro attempts to go beyond this broad application to offer a specific program of reform, based upon a critical practice, for the institution with which he was then associated. Peterat's work is more generally critically reflective, as she links the meaning of the pilot curriculum in home economics and the meaning of teaching for the teachers with feminist scholarship. She concludes that the objectification of teaching in the curriculum of the pilot runs counter to women's experience of teaching.

In trying to understand the application of my own study to the curriculum field, I am forced to reconsider my understanding of what action is. Action may easily be confused with activism rather than a change in consciousness. Of course, there are some obvious limitations to the influence that the conversations on the meaning of curriculum implementation could have on the actual implementation of a new social studies curriculum. However, there is considerable potential for our future thinking concerning implementation as a taken for granted process in schools. To give one example, both the experience of conversation and the questioning of the possibility of implementing something called "a social inquiry curriculum," showed that practice requires a continuing critically reflective discourse by teachers to achieve a consistency of action and intention.

Doing research in a conversational mode changes the relationship between persons who have been hitherto labeled as "researcher" and "practitioner." While it is unlikely to totally abolish the distinctions between them, conversational research does offer the possibility of developing a community of cooperative investigation into significant educational questions. This alone will contribute to the breaking down of rigid instrumentalist notions which separate the job of teaching from the activity of research.

During the course of establishing a new relationship between research and teaching, new and important questions of ethics are raised. Direct contact in ongoing conversation should produce a greater trust between researcher and practitioner, but the responsibility is greater too. The potential for harm to the practitioner is very real should this trust be violated. The ethical problem revolves around the development of new practices within an old research culture. The right of informed consent is a valuable protection for practitioners who become involved in research, but this right is made necessary because the activity of research has been split off from practice. Certain questions of validity also pose some difficulties for conversational research. Conventional questions of validity are epistemological in nature; for example, how do you know that the person is telling you the truth? and do the partners in conversation possess valid knowledge of what they are talking about? Conversational research, as described here, is rooted in ontological 
justifications. But flying above the epistemological question will not cause it to disappear.

Paul Ricoeur has criticised the ontological turn taken in the philosophy of Heidegger and Gadamer as being "the most unhappy that one can think of, for a philosophy which breaks dialogue with these [explanatory] sciences is left only with itself" (1973, p. 125). Ricoeur has sought to restore a dialogue between explanation and understanding by envisaging an "interpretive arc" which alternates between moments of naive understanding, explanation, and appropriation. In the four studies under consideration here, forms of the dialectic between explanation and understanding do take place. This happens both within the conversations themselves and during the course of the researcher's interpretations of these conversations. Within the conversations there are many instances of the participants (researcher and partner) questioning one another over the consistency and the accuracy of statements. A more usual form of explanatory questioning tended to follow the conversations when the researchers endeavored to make sense of the kinds of relationships and connections drawn within the conversations by relating the talk to the research literature. However, the stance taken towards the literature is most often a critical one.

Fundamentally, conversational research as practiced in these studies makes possible a deeper understanding of the reality of our situations as educators. These conversations go beyond mere explanation to demonstrate that our assumptions that we may exert total control over the educational process is illusory. By appropriating this understanding to our lives as educators we learn humility and reveal afresh some old insights. We see that beyond the policy statements and directives of curricula there lurks a more basic meaning of teaching as a deeply moral human activity.

In the final analysis, the practice of conducting conversations with participants is in itself a form of action which helps forge a reformed practice. By engaging in conservation researchers are helping to create spaces within educational institutions for thoughtful reflection oriented towards improving practice.

\section{References}

Barthes, R. (1978). A lover's discourse. New York: Hill and Wang.

Barthes, R. (1979). Presentation. Communication. 30, 3-5.

Berman, P., \& McLaughlin, M. (1976, March). Implementation of educational innovation. The Educational Forum, 345-370.

Carson, T. (1984). A hermeneutical investigation of the meaning of curriculum implementation. Unpublished doctoral dissertation, University of Alberta. 
Crandall, D. (1983, November). Teachers' role in school improvement. Educational Leadership, 6-9.

Cuban, L. (1982, October). Persistent instruction: the high school classroom, 1900-1980. Phi Delta Kappan, 113-118.

Favaro, B. (1982). Re-searching the meaning of consulting. Unpublished doctoral dissertation, University of Alberta.

Fullan, M. (1982). The meaning of educational change. Toronto: OISE.

Gadamer, H. (1975). Truth and method. New York: Seabury Press.

Gadamer, H. (1981). Reason in the age of science. Cambridge: MIT Press.

Goodlad, J. (1984). A place called school. New York: McGraw Hill.

Habermas, J. (1971). Knowledge and human interests. Boston: Beacon Press.

Jackson, P. (1968). Life in classrooms. New York: Holt, Rinehart \& Winston.

Leithwood, K. (1982). Studies in curriculum decision making. Toronto: OISE.

Lortie, D. (1975). School teacher: A sociological study. Chicago: University of Chicago Press.

Mosenthal, P. (1985, November). Defining progress in educational research. Educational Researcher, 3-9.

Oakeshott, M. (1959). Poetry and the conversation of mankind. London: Bowes and Bowes.

Peterat, L. (1983). Curriculum piloting in home economics. Unpublished doctoral dissertation, University of Alberta.

Popkewitz, T.S, Tabachnik, B.R., \& Wehlage, G.G. (1982). The myth of educational change. Madison: University of Wisconsin Press.

Ricoeur, P. (1973). Ethics and culture. Philosophy Today, 17(2/4), 153-165.

Smith, D. (1983). Unpublished doctoral dissertation, University of Alberta.

Smith, J. \& Heshusius, L. (1986, January). Closing down the conversation: the end of the quantitative-qualitative debate among educational inquirers. Educational Researcher, 4-12.

Van Manen, M. (1982). Edifying theory, serving the good. Theory into practice. 21(3), 44-50. 